NASA Technical Memorandum 106521

\title{
Large-Displacement Structural Durability Analyses of Simple Bend Specimen Emulating Rocket Nozzle Liners
}

Vinod K. Arya

University of Toledo

Toledo, Ohio

and

Gary R. Halford

Lewis Research Center

Cleveland, Ohio

June 1994

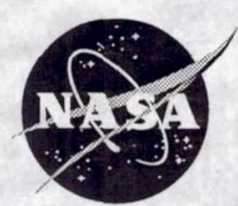

National Aeronautics and

Space Administration 


\title{
LARGE-DISPLACEMENT STRUCTURAL DURABILITY ANALYSES OF SIMPLE BEND SPECIMEN EMULATING ROCKET NOZZLE LINERS
}

\author{
Vinod K. Arya* \\ University of Toledo \\ Toledo, Ohio 43606 \\ and \\ Gary R. Halford \\ National Aeronautics and Space Administration \\ Lewis Research Center \\ Cleveland, Ohio 44135
}

\begin{abstract}
SUMMARY
Large-displacement elastic and elastic-plastic, finite-element stress-strain analyses of an oxygenfree high-conductivity (OFHC) copper plate specimen were performed using an updated Lagrangian formulation. The plate specimen is intended for low-cost experiments that emulate the most important thermomechanical loading and failure modes of a more complex rocket nozzle. The plate, which is loaded in bending at $593^{\circ} \mathrm{C}$, contains a centrally located and internally pressurized channel. The cyclic crack initiation lives were estimated using the results from the analyses and isothermal strain-controlled lowcycle fatigue data for OFHC copper. A comparison of the predicted and experimental cyclic lives showed that an elastic analysis predicts a longer cyclic life than that observed in experiments by a factor greater than 4 . The results from elastic-plastic analysis for the plate bend specimen, however, predicted a cyclic life in close agreement with experiment, thus justifying the need for the more rigorous stress-strain analysis.
\end{abstract}

\section{INTRODUCTION}

One of the important life-limiting failure modes encountered by the rocket nozzle liner of the Space Shuttle Main Engine (SSME) is thermal/mechanical ratchetting of the thin $(0.0635-\mathrm{cm})$ wall of copper material between the fuel/coolant channels and the hot gas wall. The ratchetting of material is toward the inside hot gas path of the rocket nozzle. When viewed in transverse (to the gas flow) cross section, the initially rectangular fuel/coolant channels tend to develop a "doghouse" shape with the roof pointed toward the centerline of the nozzle (see fig. 1 from ref. 1). This deformation mode feeds on itself and causes the thin wall to become ever thinner. The thinned area may rupture eventually and dump valuable hydrogen fuel into the nozzle where it is burned without a significant propulsive effect. The rate of thinning (i.e., ratchetting) has been shown analytically by Arya and Arnold (ref. 2) to be temperature. pressure, and cycle dependent. New geometric designs or new materials are required to either eliminate or drastically reduce this failure mode.

Full-scale nozzle liners are expensive to build and test for the purpose of investigating new configurations and construction materials. Thus, subscale liners that retain the important features of a

*NASA Resident Research Associate at Lewis Research Center. 
full-scale liner have been designed, built, analyzed, and tested at the NASA Lewis Research Center (refs. 3 and 4). These too are expensive to build and test. Furthermore, the turnaround time from idea (new material, new channel configuration, fabrication, etc.) to experimental verification is unacceptably long (typically about $2 \mathrm{yr}$ ). Thus, if a simpler, less expensive benchmark configuration can successfully emulate the basic structural loading and failure mode of full-size hardware, tremendous savings can be achieved.

A relatively simple (ground) plate bend specimen developed at Lewis (L.J. Westfall, 1992, NASA Lewis Research Center, Cleveland, $\mathrm{OH}$, private communication) is able to capture the essence of the loadings and failure modes found in high-heat-flux, high-thermal-conductivity rocket nozzle liners such as the Space Shuttle Main Engine (SSME). The bend specimen is a flat plate with an internally pressurized single longitudinal channel that is located along the center of the plate (fig. 2). The appendix gives the manufacturing details of this specimen.

Large-displacement tests of the plate specimen were performed isothermally at a high temperature in four-point loading to simulate the large cyclic thermal strains experienced by the full-scale nozzle liner. Bending strain gradients in the plate also simulate thermal strain gradients in the nozzle liner. That this bend specimen emulates the failure mode observed in nozzle liners is seen in figure 3 where the doghouse effect is evident: the deformed configuration of the bend specimen observed in tests performed at Lewis. Therefore, we believe that this specimen meets the requirements of a less expensive benchmark configuration that can be used to analytically assess and experimentally verify new materials and design concepts for reducing ratchetting.

This paper analytically investigates the loading and failure modes in the surrogate bend specimen. Because the ratio of the maximum deflection of the plate to its thickness is large (greater than 0.75), small-displacement analyses for the problem produced inaccurate results. Large-displacement analyses are therefore required. Although the temperature $\left(593^{\circ} \mathrm{C}\right)$ of the copper plate is in its creep range, the testing frequencies are high enough $(6.5 \mathrm{cycles} / \mathrm{min})$ to justify finite-element analyses in which the time (creep) effects are neglected. The investigations reported herein were conducted by performing largedisplacement finite-element analyses in conjunction with elastic and elastic-plastic constitutive models. The analytical results are displayed and discussed. The future direction of this research work is also discussed.

\section{FINITE-ELEMENT ANALYSES}

\section{Finite-Element Model}

The geometry and dimensions of the specimen and channel are given in figure 2. Solid eightnoded brick elements with an assumed strain formulation were utilized to model the pressurized (6.2-MPa) center channel of the specimen. Because of the geometric and loading symmetry, only onequarter of the specimen was modeled. A sensitivity study of the effect of mesh density on the results showed that a large number of elements was required for accurately capturing the high bending strain gradients. The presence of internal pressure in the channel, in addition to the bending gradients, necessitated the use of an even finer mesh in the channel region of the specimen. This finite-element model is shown in figure 4 and consists of 3330 elements and 4463 nodes.

\section{Approximate Shape of Bent Specimen (Plate)}

Only the maximum deflection occurring at the center of the plate was experimentally measured; hence, to determine the deflections at all other points of the plate (and its bent shape at maximum deflection), an approximate elastic analysis was performed by modeling the whole plate as a solid thick plate 
excluding the channel under uniform load transverse to the plate. The load was analytically increased until the calculated deflection at the center was equal to the value measured in experiments. The deflections at all other points (nodes) of the plate were also recorded at this time. These displacements were later used to perform the elastic and elastic-plastic finite-element analyses by treating these latter analyses as displacement-controlled boundary value problems. All finite-element analyses were performed by using the finite-element program MARC (ref. 5). The undeformed and (calculated) deformed shapes of the solid thick plates subject to these finite-element analyses are shown in figure 5 . The displacements shown are exaggerated by a factor of 5 .

\section{Elastic Analysis}

A one-fourth segment of the pressurized and deformed (bent) single-channel plate is shown in figure 6. The undeformed configuration is presented for comparison. Displacements are exaggerated by a factor of 5 again to clearly distinguish the two configurations. An elastic stress-strain structural analysis was performed using a finite-element discretization of this segment as described in the section FiniteElement Model. Because the problem involves large displacements of the segment in the XZ-plane, a large-displacement analysis using an updated Lagrangian formulation was adopted. The channel region of the specimen is of greatest interest; thus, only those figures that exhibit the stress and strain distributions in this region are included.

The longitudinal (X-direction) stress in the vicinity of the channel is shown in figure 7. A typical bending stress distribution is observed with tension on the upper surface, compression on the lower surface, and a neutral axis of zero stress in the middle. The maximum elastically calculated longitudinal stress in the channel is about $766 \mathrm{MPa}$. The stresses in the $\mathrm{Y}$ - and Z-directions are shown in figures 8 and 9, respectively. The $\mathrm{Y}$ - and $\mathrm{Z}$-stresses have maximum magnitudes of about 350 and $260 \mathrm{MPa}$, respectively.

The strain distribution in the channel in the X-, Y-, and Z-directions is shown in figures 10 to 12 , respectively. The maximum magnitudes of the strains occur in the X-direction (approx equal to 0.7 percent). Also seen in figure 10 is the X-strain, which is tensile in the top layer of the channel and compressive in the bottom layer. The middle of the channel has almost zero X-strain.

\section{Elastic-Plastic Analysis}

Elastically calculated stress values far exceed the 0.2 -percent offset yield strength of OFHC copper $(30.0 \mathrm{MPa})$ at $593{ }^{\circ} \mathrm{C}$. Therefore, an elastic analysis of the problem is inappropriate and may lead to erroneous results. Obviously, inelastic constitutive behavior must be taken into consideration. Keeping this in mind, a large-displacement elastic and perfectly plastic finite-element analysis of the segment was performed. As in the case of the elastic analysis, the large-displacement elastic-plastic analysis is also based on an updated Lagrangian formulation. Some important results from elastic-plastic analysis are presented here.

The X-stress distribution in the channel obtained from an elastic-plastic analysis is shown in figure 13. The maximum X-stress of $46.4 \mathrm{MPa}$ contrasts with $766 \mathrm{MPa}$ obtained from an elastic analysis. The $\mathrm{Y}$ - and $\mathrm{Z}$-stress distributions in the channel are shown in figures 14 and 15, respectively. The maximum $\mathrm{Y}$ - and Z-stress magnitudes calculated from an elastic-plastic analysis are 34.2 and $14.9 \mathrm{MPa}$, respectively. The stress values obtained from an elastic-plastic analysis are significantly more realistic than those obtained from the elastic analysis.

The total X-, Y-, and Z-strain distributions in the channel are shown in figures 16 to 18 . As expected, the $\mathrm{X}$-strain is tensile in the top layer and compressive in the bottom layer. Similarly, because of Poisson's effect, the Z-strain is compressive in the top layer and tensile in the bottom layer (fig. 18). 
Figure 19 shows only the plastic component of the X-strain in the channel. A comparison of this figure with figure 16 reveals that the deformation of the channel is largely plastic.

\section{Life Analysis}

The cyclic crack initiation life of the bend specimen was estimated by using the results from large elastic and large elastic-plastic structural analyses. Following the procedure of Manson and Halford (ref. 6), the maximum total strain ranges at the critical locations of the bend specimen were estimated by using the following expressions:

effective stress:

$$
\sigma_{e}=\frac{1}{\sqrt{2}}\left[\left(\sigma_{1}-\sigma_{2}\right)^{2}+\left(\sigma_{2}-\sigma_{3}\right)^{2}+\left(\sigma_{3}-\sigma_{1}\right)^{2}\right]^{1 / 2}
$$

and

effective strain:

$$
\varepsilon_{e}=\frac{\sqrt{2}}{3}\left[\left(\varepsilon_{1}-\varepsilon_{2}\right)^{2}+\left(\varepsilon_{2}-\varepsilon_{3}\right)^{2}+\left(\varepsilon_{3}-\varepsilon_{1}\right)^{2}\right]^{1 / 2}
$$

The values of maximum total strain range for the bend specimen obtained from the elastic and elasticplastic analyses are listed in table I.

TABLE I.-EXPERIMENTAL AND PREDICTED

CYCLIC LIVES OF PLATE BEND SPECIMEN

\begin{tabular}{|l|c|c|}
\hline \multicolumn{1}{|c|}{ Analysis } & $\begin{array}{c}\text { Maximum total effective } \\
\text { strain range, } \\
\text { percent }\end{array}$ & $\begin{array}{c}\text { Life, } \\
\text { cycles }\end{array}$ \\
\hline Large elastic & 1.1 & 500 \\
Large elastic-plastic & 1.7 & 190 \\
Experiment & $\cdots--$ & 109 \\
\hline
\end{tabular}

Conway, Stentz, and Berling (ref. 7) reported isothermal, strain-controlled, low-cycle fatigue test results for annealed, oxygen-free, high-conductivity copper at $538^{\circ} \mathrm{C}$ in a nonoxidizing argon atmosphere. These results are shown in figure 20 as total effective strain range versus cycles to crack initiation. The data were generated at a cyclic strain rate of $0.002 \mathrm{~s}^{-1}$. Because this strain rate is about the same (half) as that experienced by the bend specimen, the data of reference 7 at $538^{\circ} \mathrm{C}$ can reasonably be applied to the assessment of the cyclic life for the bend specimen. Outputs from the elastic and elasticplastic analyses give the total maximum effective strain ranges at the critical locations of the specimen as 1.1 and 1.7 percent, respectively (see table I). From figure 20, these strain ranges are shown to correspond to cyclic lives of 500 and 190, respectively. Note that the maximum total effective strain ranges were determined from the results of elastic and elastic-plastic finite-element analyses performed at $593{ }^{\circ} \mathrm{C}$ as were the tests for the OFHC copper specimens. The experimental data reported in reference 7, however, 
were obtained at $538{ }^{\circ} \mathrm{C}$. Because no experimental data from OFHC copper are available at $593{ }^{\circ} \mathrm{C}$, the $538^{\circ} \mathrm{C}$ data were used to assess the cyclic life for the specimen. The justification for using the experimental data at $538^{\circ} \mathrm{C}$ to predict the cyclic lives from the results of analyses performed at $593{ }^{\circ} \mathrm{C}$ lies in the fact that the tensile ductility of OFHC copper is insensitive to temperature (variations measured at Lewis range from an 81- to 89-percent reduction of area). The low-cycle fatigue resistance is, therefore, also expected (ref. 8) to be insensitive to temperature over the range of interest.

Westfall (1992, NASA Lewis, Cleveland, OH, private communication) experimentally determined the cyclic life of the bend specimen to be 109 at $593^{\circ} \mathrm{C}$. The elastic analysis predicts a longer cyclic life than that observed in experiments by more than a factor of 4 . Although the elastic-plastic analysis also predicts a longer cyclic life for the bend specimen, the agreement between the prediction and experiment is much closer. Because the life predictions are based on a pure fatigue failure mode (exclusive of ratchetting), it is not surprising that the predictions exceeded the experimentally observed cyclic lives.

\section{SUMMARY}

Large-displacement elastic and elastic-plastic finite-element analyses were presented for a grooved plate bend specimen. The analyses incorporate an updated Lagrangian formulation. Using the results from these elastic and elastic-plastic finite-element analyses, the cyclic lives for crack initiation are assessed for the bend specimen. The elastic analysis predicted a longer cyclic life for the specimen than that observed in experiments by a factor of more than 4 . The elastic-plastic analysis also predicted a longer cyclic life than that observed, but the prediction was in closer agreement with the experimentally determined cyclic life.

\section{FUTURE WORK}

Large-deformation elastic analysis predicts a longer cyclic life for a grooved specimen than that observed in experiments. In contrast, elastic-plastic analysis predicts cyclic life much closer to the experimental result. Time (creep) effects were assumed insignificant and were excluded from the analyses. It is intended that the life prediction methodology described in this report be applicable to the SSME rocket nozzle liner. The period of a laboratory specimen test cycle is about $9 \mathrm{sec}$. The period of thermomechanical loading cycle experienced by the SSME rocket nozzle liner is more than $480 \mathrm{sec}$. An accurate assessment of the structural response of a bend specimen that emulates the realistic thermomechanical loading cycle experienced by an SSME nozzle liner will require time-dependent inelastic analysis. In this regard, viscoplastic models provide more accurate descriptions and assessments of inelastic response than those of conventional elastic-plastic (creep) models. It is therefore proposed that a 480 -sec loading cycleimposed viscoplastic finite-element analysis be performed for the bend specimen for future cyclic life assessment. Furthermore, to assess the creep-fatigue failure mode life for loading cycles experienced by the SSME rocket nozzle liners, laboratory material tests with durations of the order of $480 \mathrm{sec} / \mathrm{cycle}$ would be essential. 


\section{APPENDIX-FABRICATION OF COPPER PLATE SPECIMENS}

Oxygen-free high-conductivity (OFHC) copper sheets, 0.3175 and $0.0889 \mathrm{~cm}$ thick, were cut into 5.08 - by $15.24-\mathrm{cm}$ sections to match the 5.08 - $\mathrm{cm}$-wide channel die used for specimen fabrication. The thicker sheets were machined to produce a center chamber, 0.3175 by $5.08 \mathrm{~cm}$, with a thin gas transport passage (shown in fig. 2). A 10.16-cm-long, 0.3175-cm-diameter stainless steel tube was inserted $5.08 \mathrm{~cm}$ into the gas transport passage to produce a gas pathway to the center chamber.

Prior to assembly operations, all surfaces of the copper sheets were mechanically cleaned with fine sandpaper to remove any copper oxide. Nickel-palladium (Ni-35.32Pd-9.63Cr-4.63Fe2.69B) brazing foil, $0.00381 \mathrm{~cm}$ thick, was used for pressure brazing the two sheets together. This brazing alloy melts at a temperature between 945 and $996^{\circ} \mathrm{C}$. Fifteen-cm-long sheets of the foil were cut and machined to produce a hole that matched the center chamber of the thick copper sheet. The brazing foil was secured to both surfaces of the thick copper sheet by a liquid brazing flux which acted as an adhesive. A debonding agent or $\mathrm{Al}_{2} \mathrm{O}_{3}$ wool was placed in the center chamber to prevent the flow of brazing material into the chamber. Thin copper sheets were placed on top of the brazing foil and secured with tape or copper rivets at the four corners. The three-sheet assembly was covered with a release agent and placed into a vacuum hot press containing a $5.08-\mathrm{cm}$-wide channel die. The assembly was vacuum hot pressed (pressure brazed) by heating the die containing the sample to $982^{\circ} \mathrm{C}$ under a pressure of $3.4475 \mathrm{MPa}$ in a vacuum of $5 \times 10^{-5}$ torr for a hold time of $1 \mathrm{hr}$.

\section{REFERENCES}

1. Jankovsky, R.S.; Arya, V.K.; Kazaroff, J.M.; and Halford, G.R.: Structurally-Compliant Rocket Engine Combustion Chamber-Experimental/Analytical Validation. NASA TP-3431, 1994.

2. Arya, V.K.; and Arnold, S.M.: Viscoplastic Analysis of an Experimental Cylindrical Thrust Chamber Liner. AIAA Journal. 30, 3, 1992, pp. 781-789.

3. Quentmeyer, R.J.: Experimental Fatigue Life Investigation of Cylindrical Thrust Chambers. NASA TMX-73665, 1977.

4. Kazaroff, J.M.; Jankovsky, R.J.; and Pavli, A.J.: Hot Fire Test Results of Subscale Tubular Combustion Chambers. NASA TP-3222, 1992.

5. MARC General Purpose Finite Element Program. MARC Research Analysis Corporation, Palo Alto, 1992.

6. Manson, S.S.; and Halford, G.R.: Treatment of Multiaxial Creep-Fatigue by Strainrange Partitioning. Symp. Creep-Fatigue Interaction. (Edited by R.M. Curran), pp. 299-322. Am. Soc. Mech. Engrs., New York, 1976.

7. Conway, J.B.; Stentz, R.H.; and Berling, J.T.: High Temperature, Low-Cycle Fatigue of Copper-Base Alloys in Argon; Part I-Preliminary Results for 12 Alloys at $1000^{\circ} \mathrm{F}\left(538^{\circ} \mathrm{C}\right)$. NASA CR-121259, 1973.

8. Halford, G.R.; Hirschberg, M.H.; and Manson, S.S.: Temperature Effects on Strainrange Partitioning Approach for Creep-Fatigue Analysis. In Fatigue at Elevated Temperatures (edited by A.E. Carden, A.J. McEvily, and C.H. Wells), ASTM STP-520, 1973, pp. 658-667. 


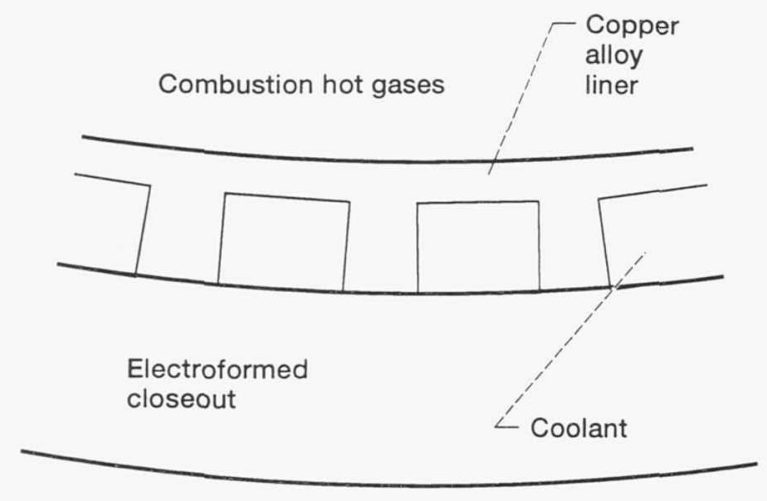

(a)

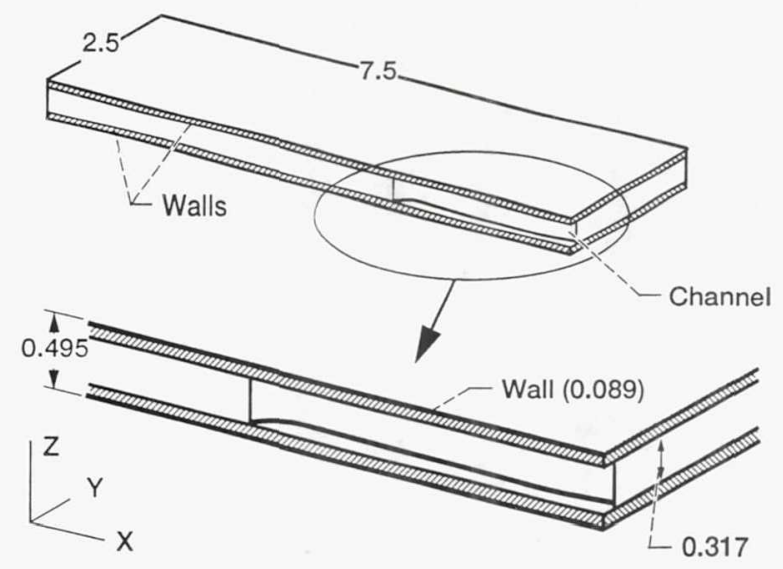

Figure 1.-Thrust chamber coolant channels before and after deformation (ref. 1). (a) Before. (b) After.

Figure 2.-Plate bend specimen (one-quarter). (All dimensions are in centimeters.)

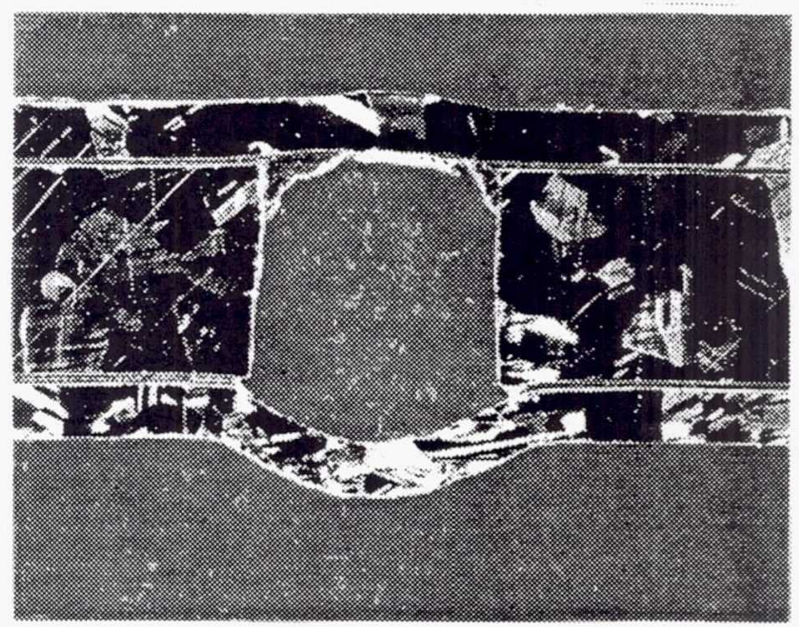

Figure 3.-Deformed channel of plate specimen showing "doghouse" effect. 

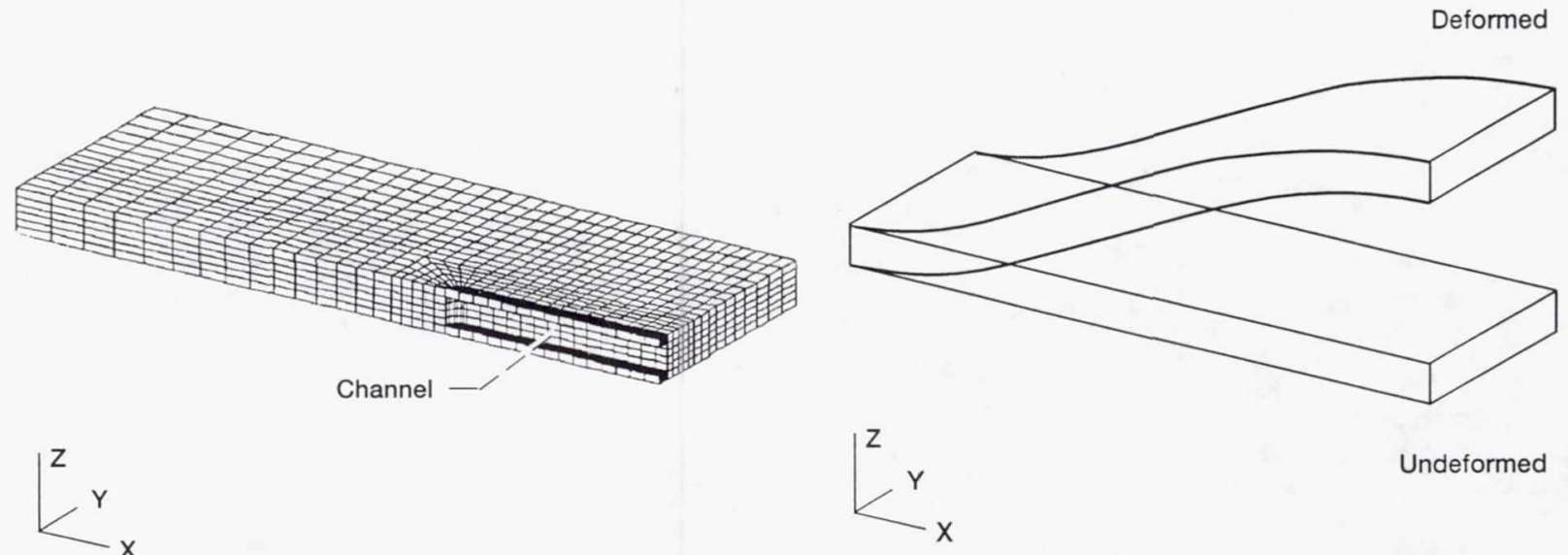

Figure 5.-Undeformed and deformed shapes of thick plate. (Deformations are magnified by a factor of 5.)

Figure 4.-Finite-element model of plate bend specimen ( 3330 elements; 4463 nodes).

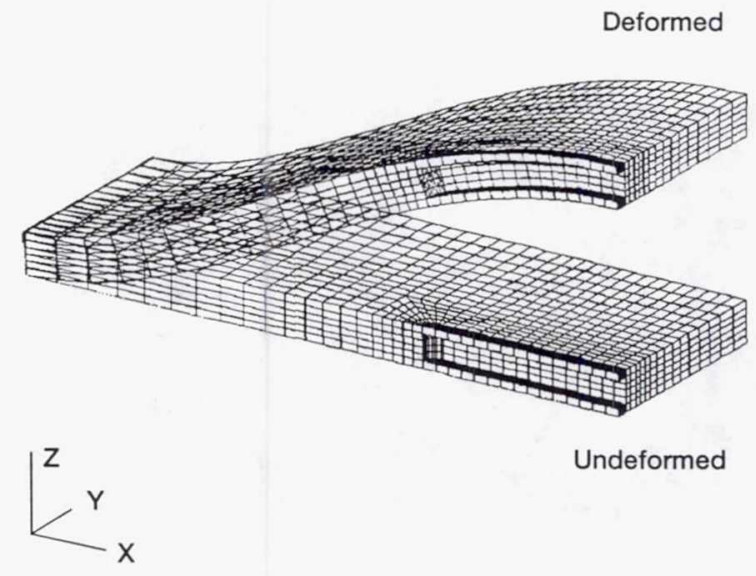

Figure 6.-Deformed and undeformed shapes of segment. (Deformations are magnified by a factor of 5 .) 


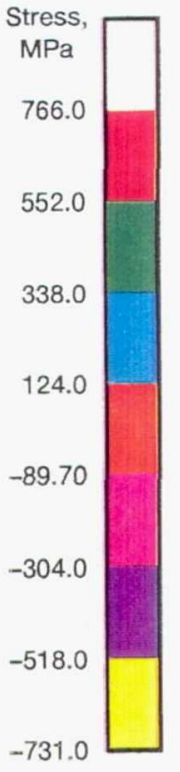

Figure 7.-X-stress in channel wall; elastic analysis.
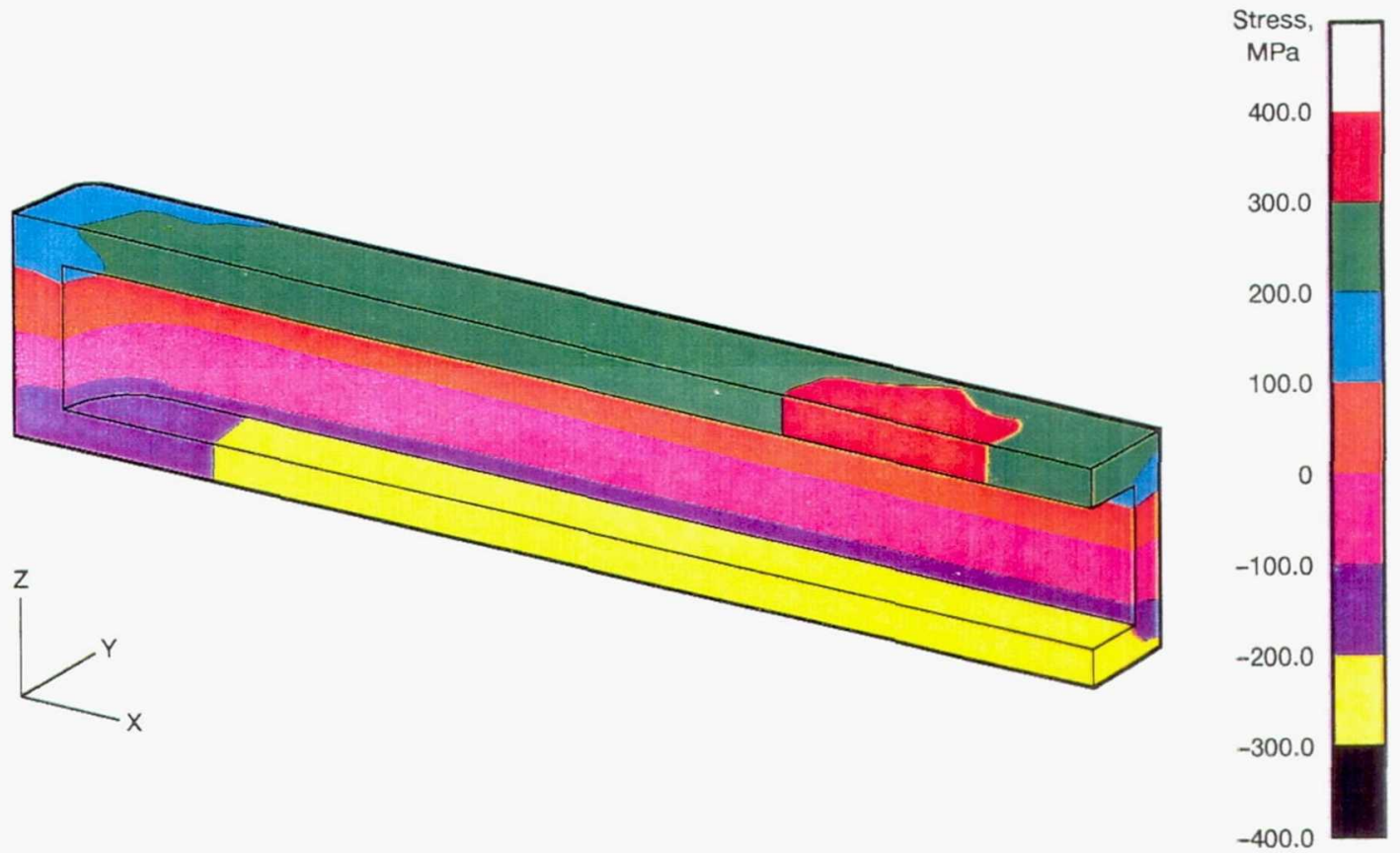

Figure 8.-Y-stress in channel wall; elastic analysis. 
Page intentionally left blank 

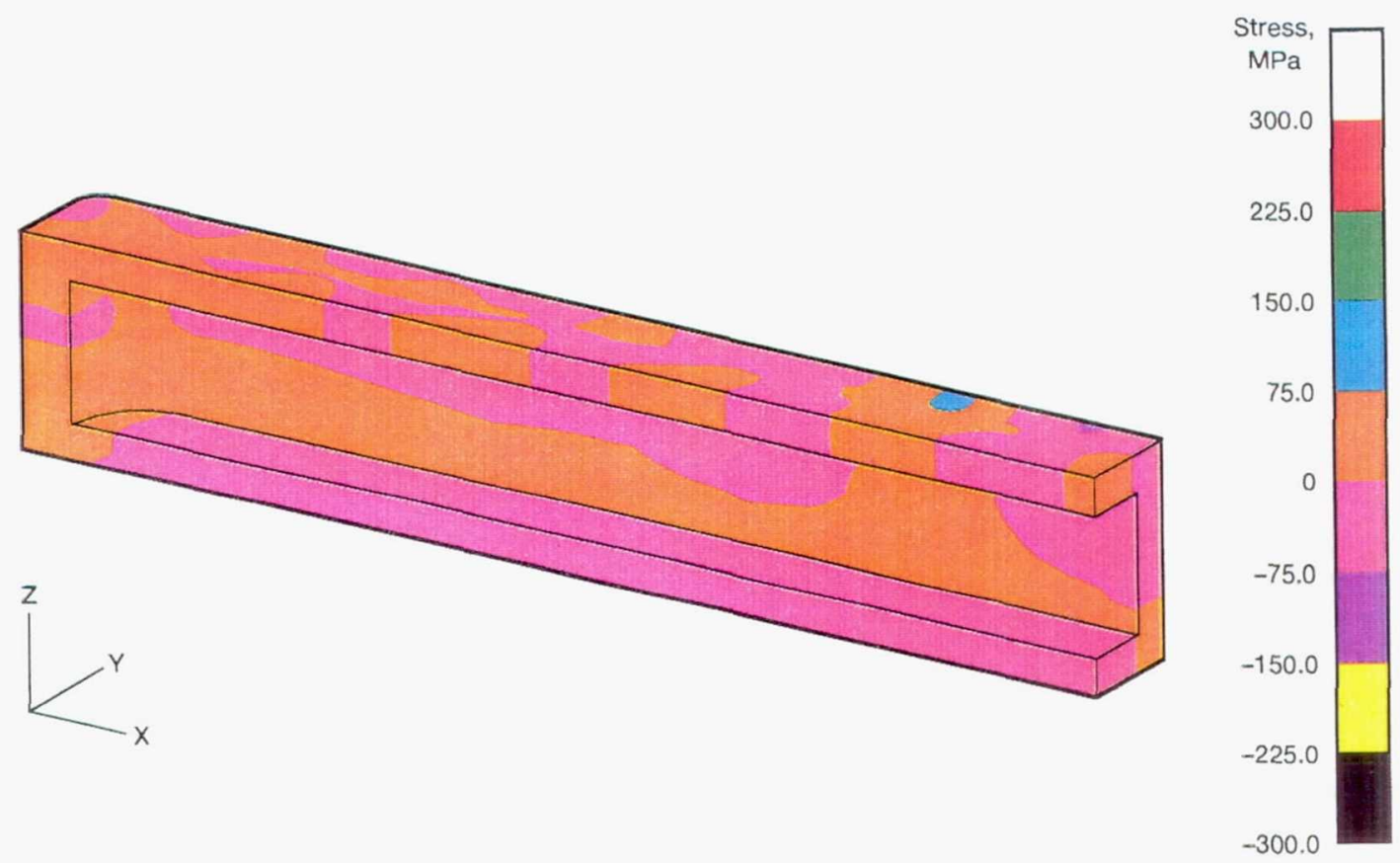

Figure 9._-Z-stress in channel wall; elastic analysis.
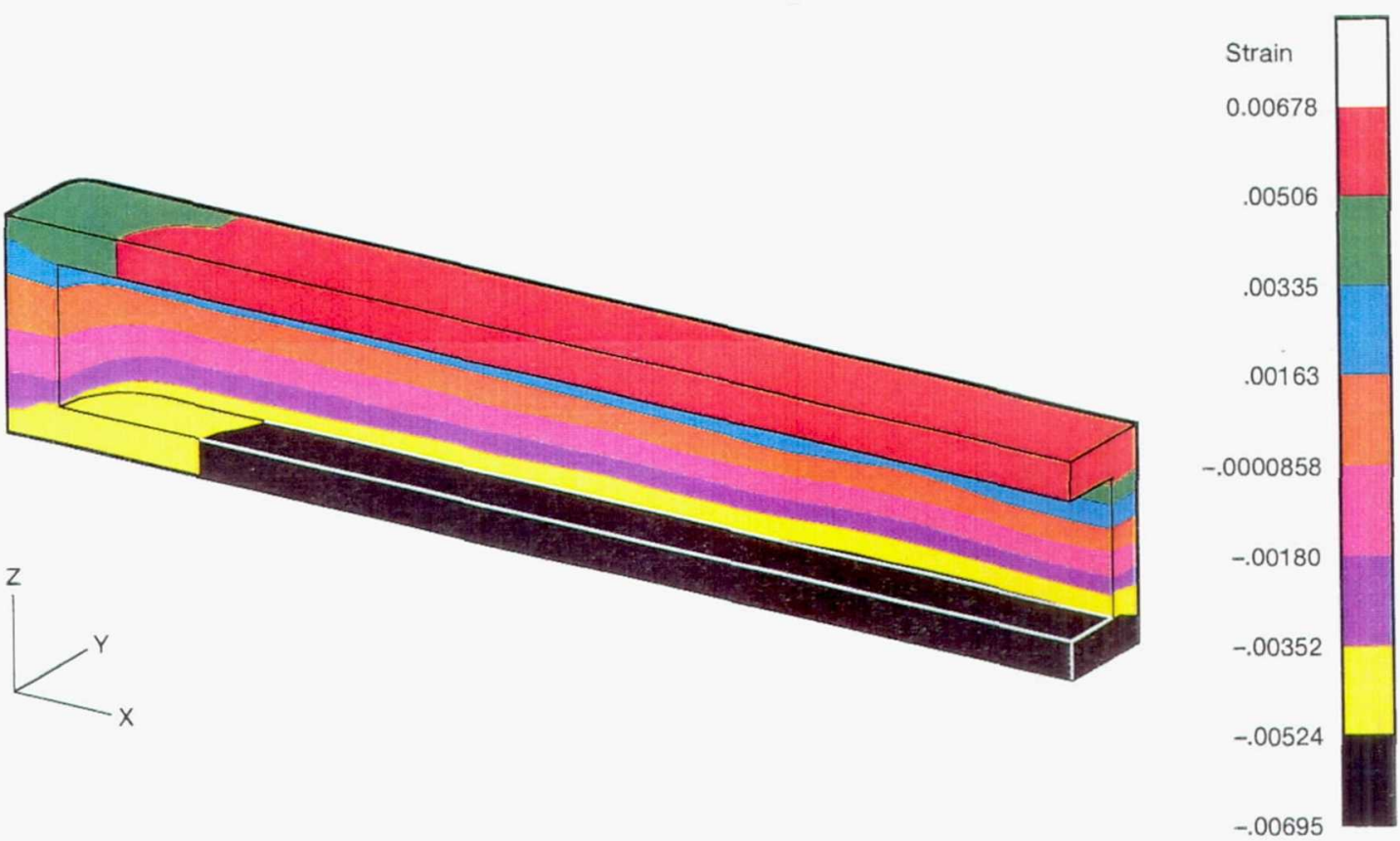

Figure 10.-X-strain in channel wall; elastic analysis. 
Page intentionally left blank 

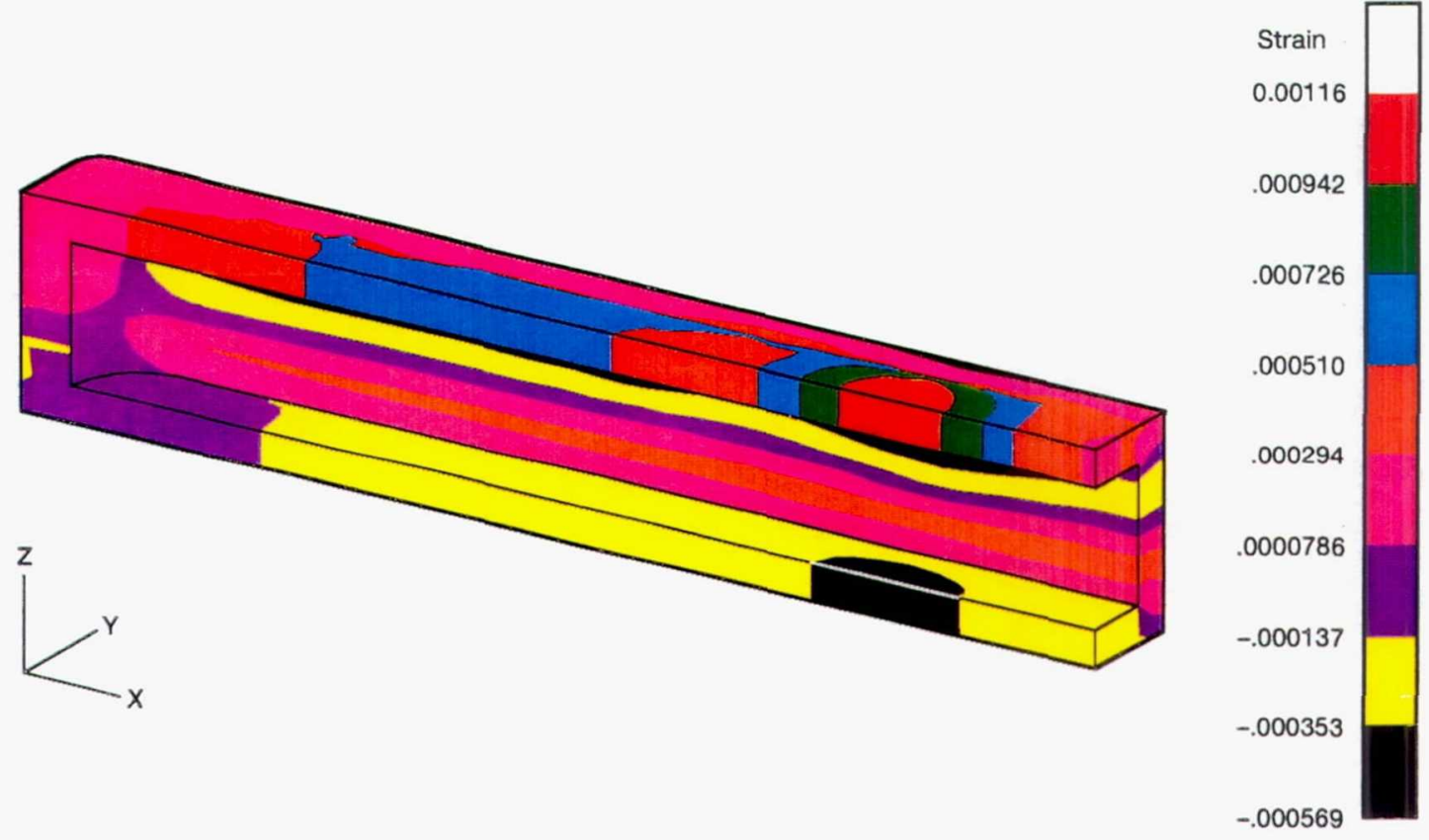

Figure 11.-Y-strain in channel wall; elastic analysis.
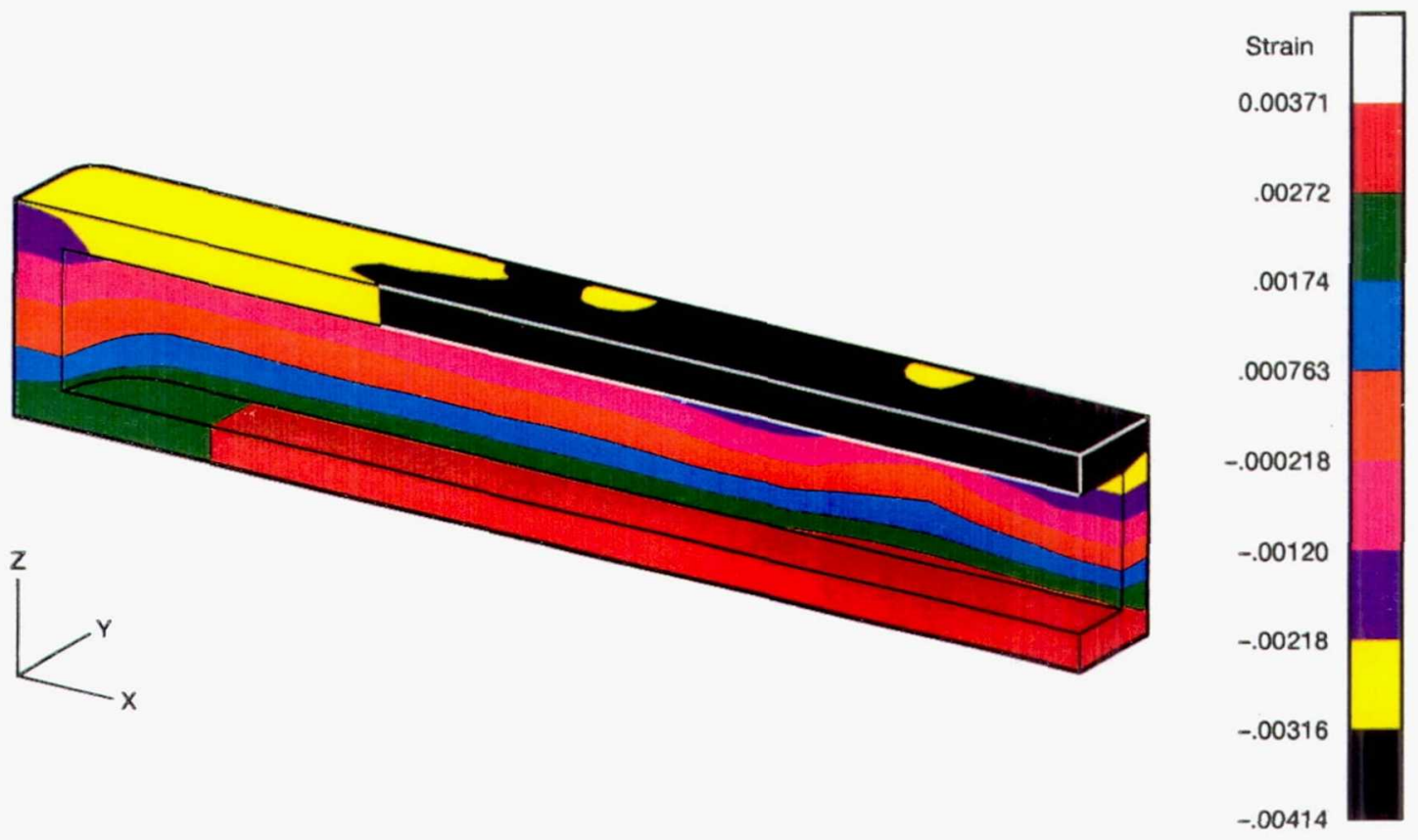

Figure 12.-Z-strain in channel wall; elastic analysis. 
Page intentionally left blank 

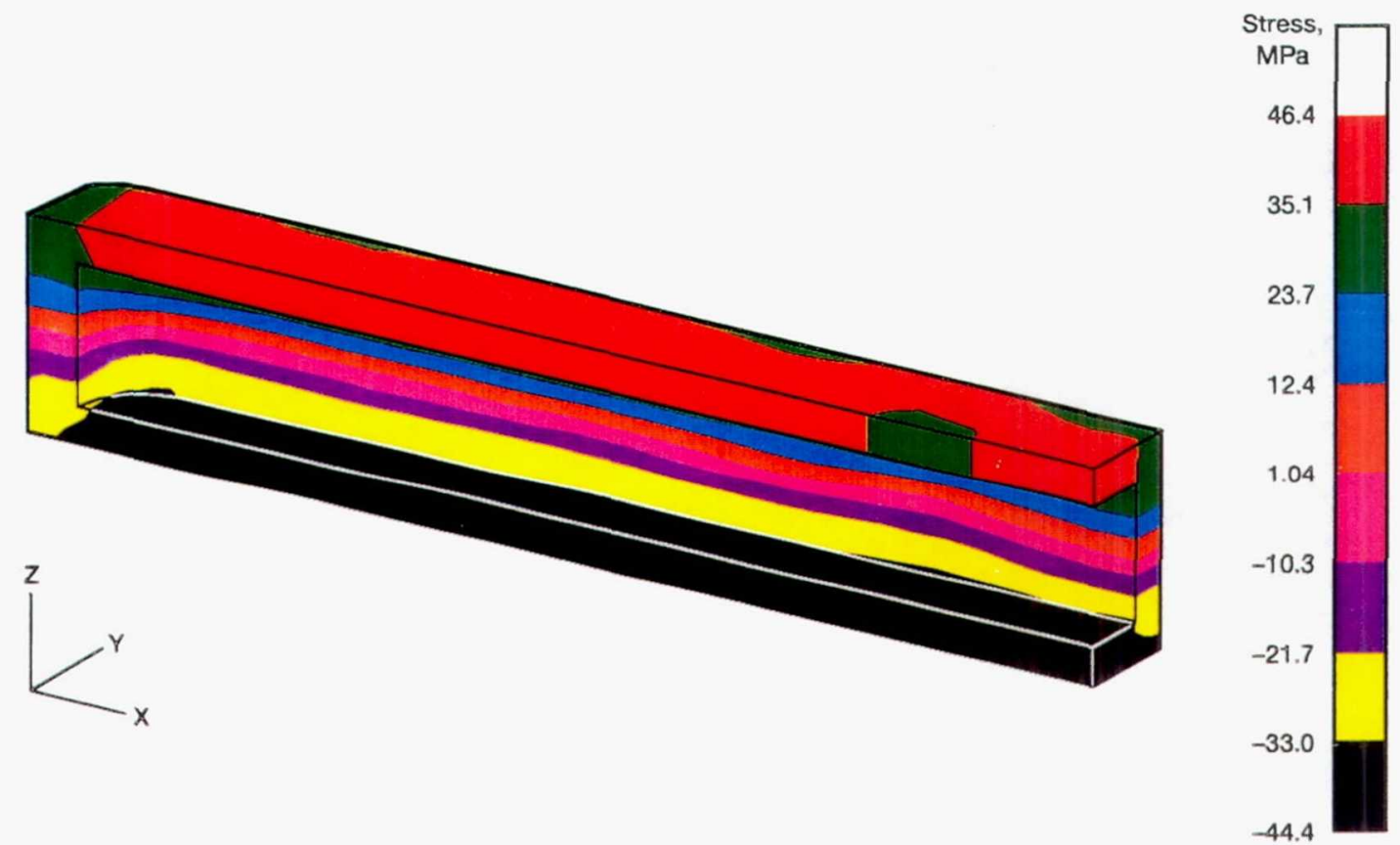

Figure 13.-X-stress in channel wall; elastic-plastic analysis.
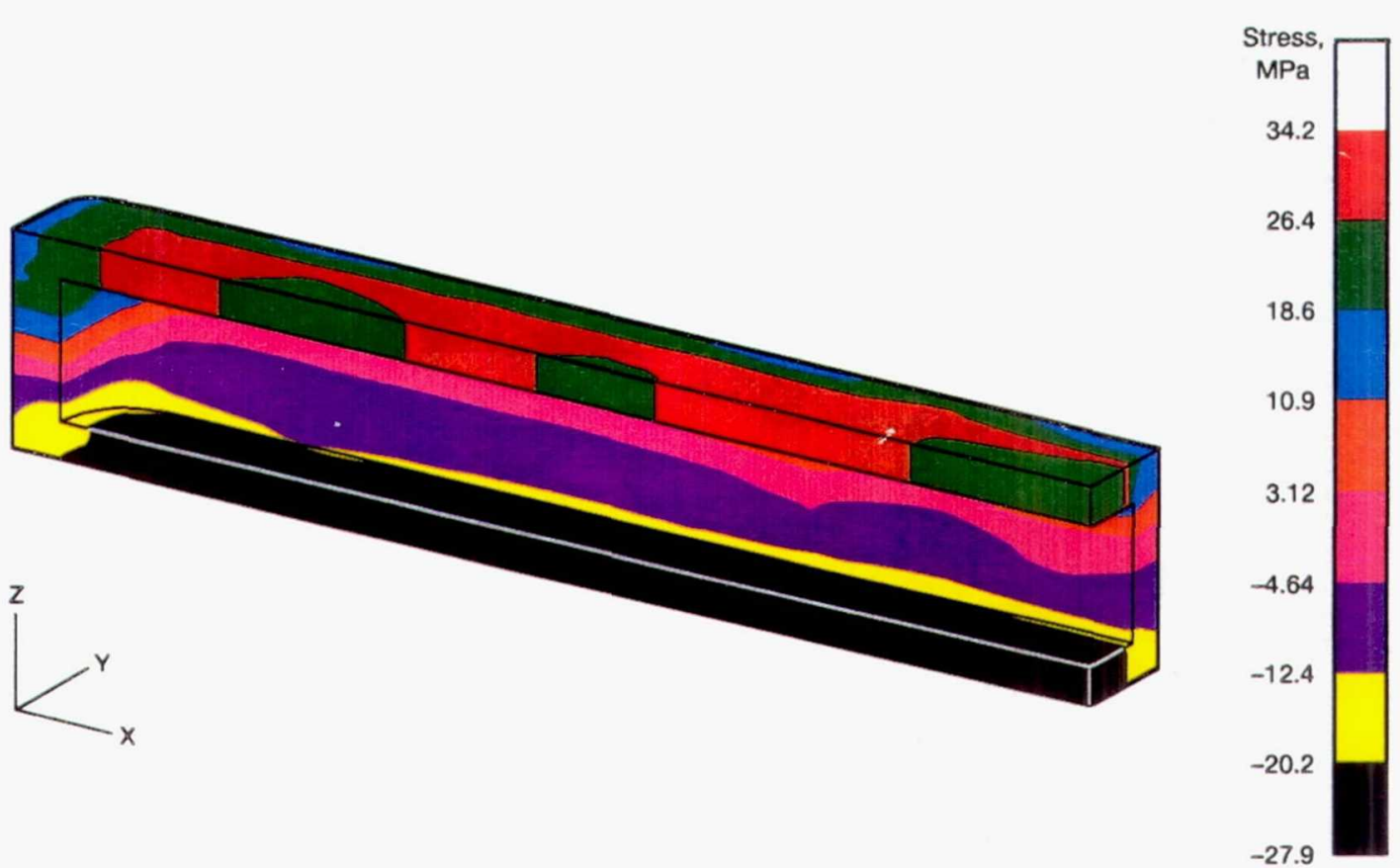

Figure 14.-Y-stress in channel wall; elastic-plastic analysis. 
Page intentionally left blank 

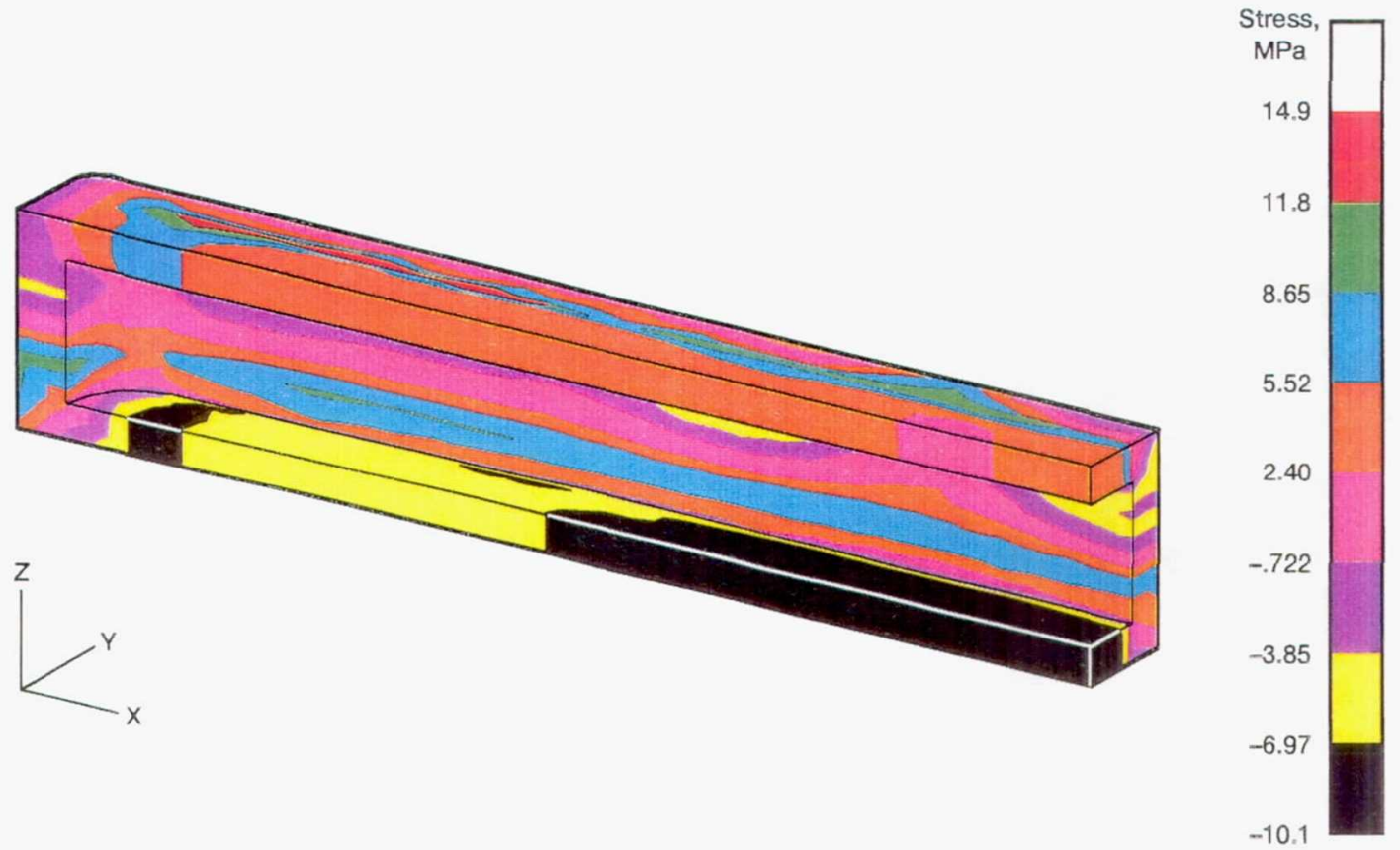

Figure $15,-Z$-Stress in channel wall; elastic-plastic analysis.
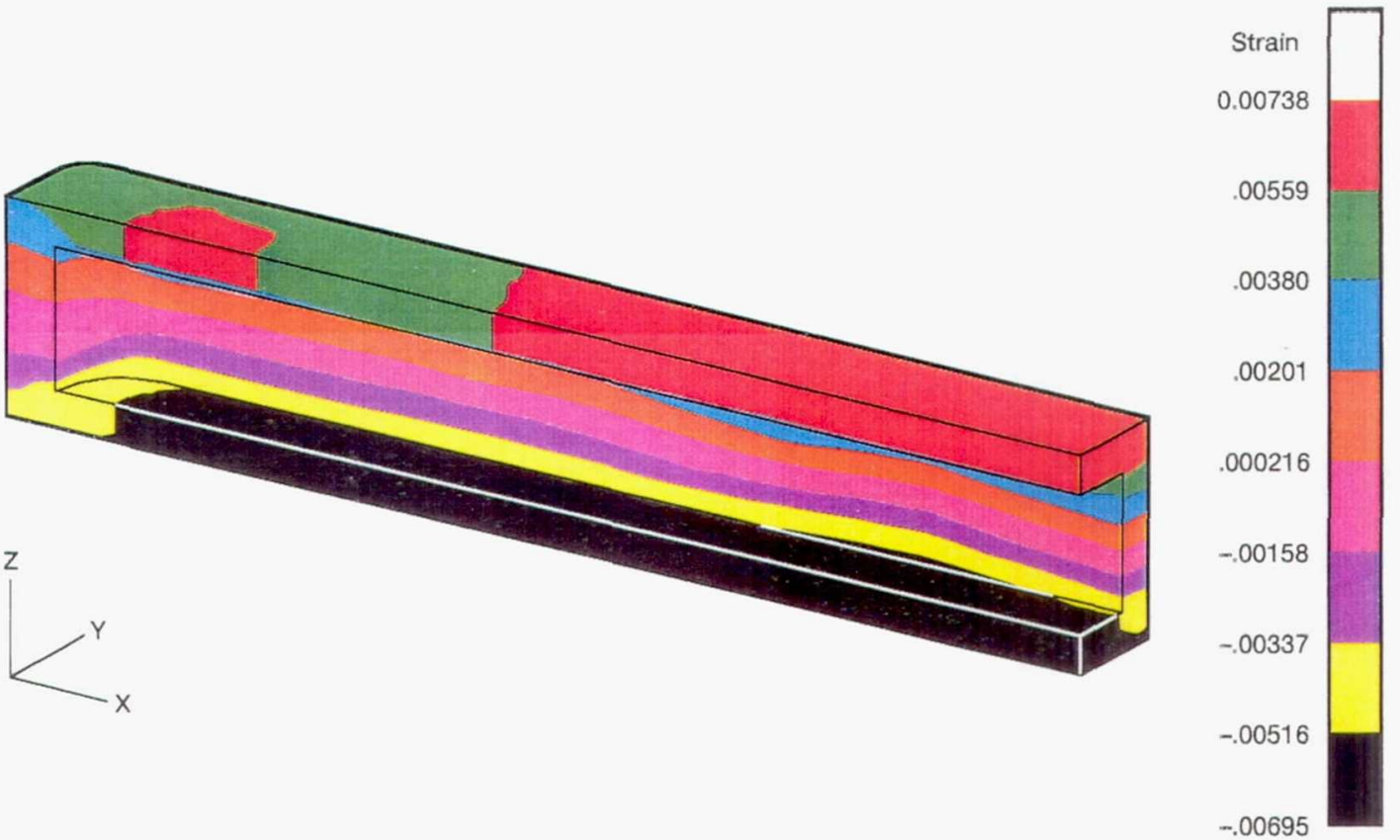

Figure 16.-Total X-strain in channel wall; elastic-plastic analysis. 
Page intentionally left blank 


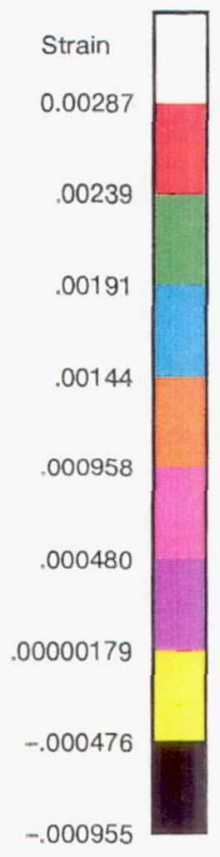

Figure 17.-Total Y-strain in channel wall; elastic-plastic analysis.
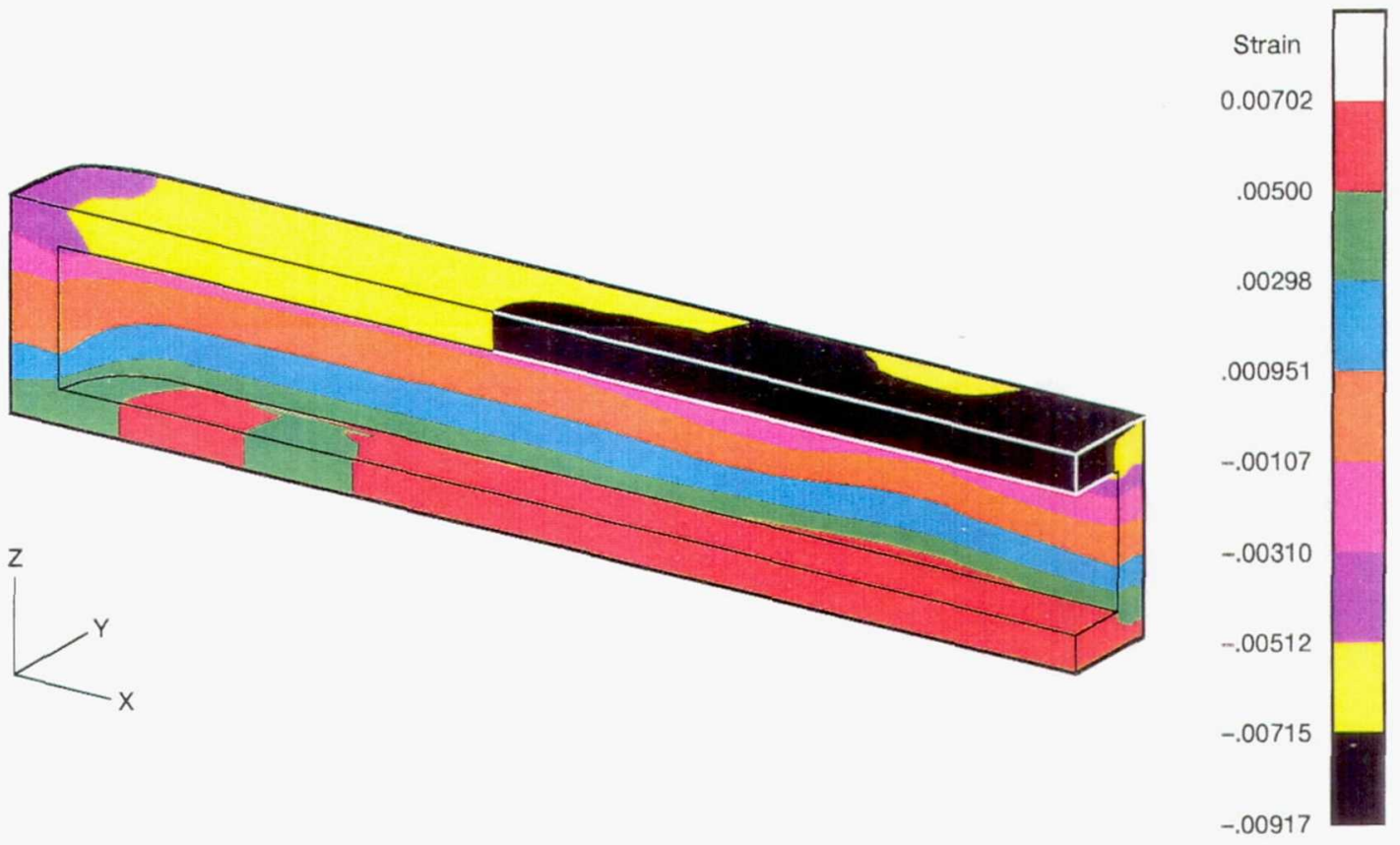

Figure 18.--Total Z-strain in channel wall; elastic-plastic analysis. 
Page intentionally left blank 

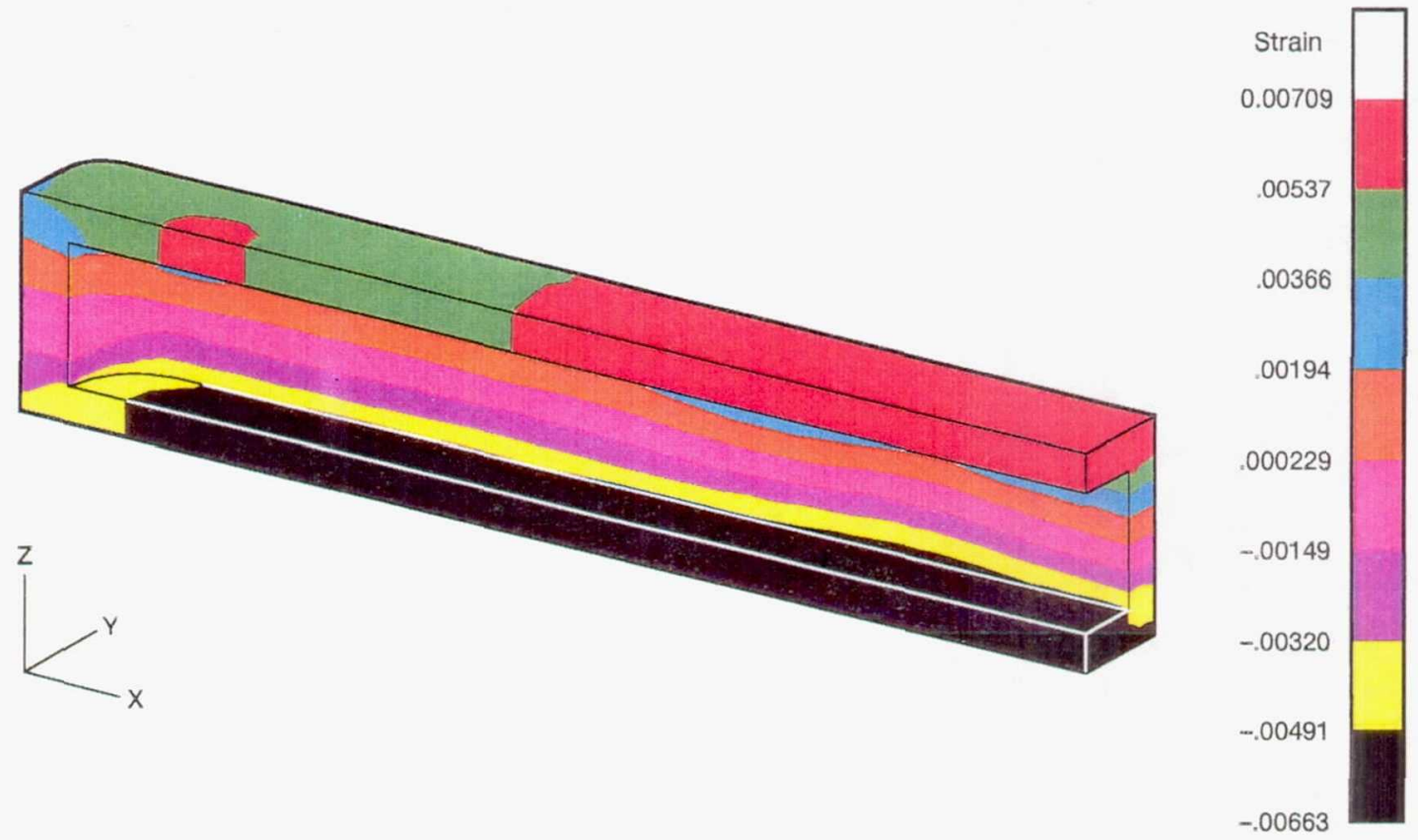

Figure 19.--Plastic X-strain in channel wall; elastic-plastic analysis. 
Page intentionally left blank 


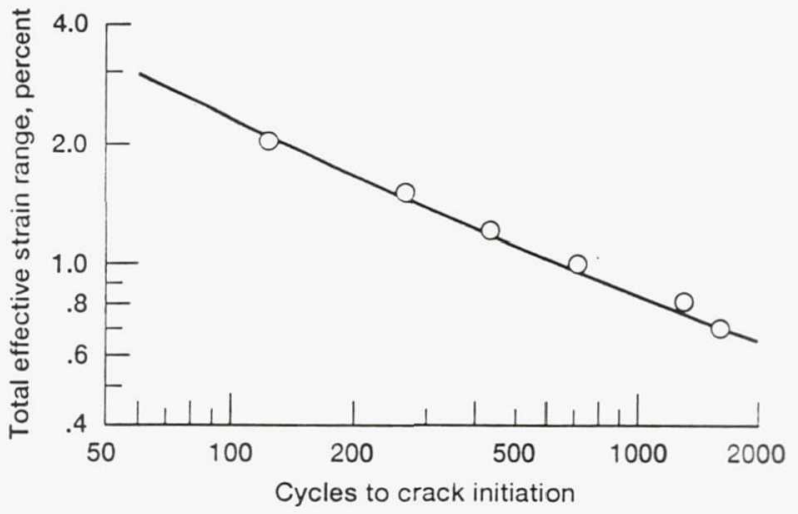

Figure 20.-Low-cycle fatigue resistance of oxygen-free, highconductivity (OFHC) copper at $538^{\circ} \mathrm{C}$ in argon at cyclic strain 
Public reporting burden tor inis collection of intormation is estimated to average 1 hour per resoonse, inciuding the time tor reviewing instructions. searching existing data sources. gathering and maintaining the data needed. and completing and reviewing the collection of intormation. Send comments regarding this ourden estimate or any other aspect of this collection of intormation. including suggestions for reducing this burden, to Washington Headquarters Services. Directorate for Information Operations and Reports. 1215 Jefferson Davis Highway, Suite 1204. Arlington, VA 22202-4302, and to the Office of Management and Budget, Paperwork Reduction Project (0704-0188), Washington. DC 20503.
1. AGENCY USE ONLY (Leave blank)
2. REPORT DATE
June 1994
3. REPORT TYPE AND DATES COVERED
Technical Memorandum
5. FUNDING NUMBERS

\section{TITLE AND SUBTITLE}

Large-Displacement Structural Durability Analyses of Simple Bend Specimen

Emulating Rocket Nozzle Liners

\section{6. $\operatorname{AUTHOR}(\mathrm{S})$}

Vinod K. Arya and Gary R. Halford

\section{PERFORMING ORGANIZATION NAME(S) AND ADDRESS(ES)}

National Aeronautics and Space Administration

Lewis Research Center

Cleveland, Ohio 44135-3191

9. SPONSORING/MONITORING AGENCY NAME(S) AND ADDRESS(ES)

National Aeronautics and Space Administration

Washington. D.C. 20546-0001
WU-505-63-5B
8. PERFORMING ORGANIZATION REPORT NUMBER

E-8644

11. SUPPLEMENTARY NOTES

Vinod K. Arya, University of Toledo, Toledo, Ohio 43606 and NASA Resident Research Associate at Lewis Research Center (work funded by NASA Contract NCC3-120) and Gary R. Halford, NASA Lewis Research Center. Responsible person, Gary R. Halford, organization code 5200, (216) 433-3265.

12a. DISTRIBUTION/AVAILABILITY STATEMENT

12b. DISTRIBUTION CODE

Unclassified - Unlimited

Subject Category 39

13. ABSTRACT (Maximum 200 words)

Large-displacement elastic and elastic-plastic. finite-element stress-strain analyses of an oxygen-free high-conductivity (OFHC) copper plate specimen were performed using an updated Lagrangian formulation. The plate specimen is intended for low-cost experiments that emulate the most important thermomechanical loading and failure modes of a more complex rocket nozzle. The plate, which is loaded in bending at $593{ }^{\circ} \mathrm{C}$, contains a centrally located and internally pressurized channel. The cyclic crack initiation lives were estimated using the results from the analyses and isothermal strain-controlled low-cycle fatigue data for OFHC copper. A comparison of the predicted and experimental cyclic lives showed that an elastic analysis predicts a longer cyclic life than that observed in experiments by a factor greater than 4. The results from elastic-plastic analysis for the plate bend specimen. however, predicted a cyclic life in close agreement with experiment, thus justifying the need for the more rigorous stress-strain analysis.

\section{SUBJECT TERMS}

Finite-element analysis; Rocket nozzle liner; Bend specimen; Large displacement: Elastic-plastic analysis

\begin{tabular}{|c|c|}
\hline $\begin{array}{c}\text { 17. SECURITY CLASSIFICATION } \\
\text { OF REPORT } \\
\text { Unclassified }\end{array}$ & $\begin{array}{c}\text { 18. SECURITY CLASSIFICATION } \\
\text { OF THIS PAGE } \\
\text { Unclassified }\end{array}$ \\
\hline
\end{tabular}
19. SECURITY CLASSIFICATION OF ABSTRACT Unclassified

